\title{
Biomedical Research during the COVID-19 pandemic: success in SARS-CoV-2 and other infectious diseases
}

\author{
Nuno S. Osório ${ }^{1 *}$, Maria Isabel Veiga ${ }^{1}$ \\ 1 Life and Health Sciences Research Institute (ICVS), School of Medicine, University of Minho, Campus Gual- \\ tar, 4710-057 Braga, Portugal. \\ * Correspondence: nosorio@med.uminho.pt
}

\begin{abstract}
It is known for decades that viruses from the Coronoviridae family can adapt to human-tohuman transmission. In 2020, SARS-CoV-2 caused a global pandemic of unprecedented scale imposing the loss of millions of human lives and being at the heart of a global economic crisis. Thus, we overviewed key research advances generated from the identification of the etiological agent to a better understanding of its origin, evolution and factors underlying global spread. Furthermore, we analyze the scientific productivity using the PubMed database. We found that the total number of publications increased more than $8 \%$ in 2020 when compared with 2019 or the average publications per year in the previous quinquennial. Remarkably, 86,638 publications related with COVID19 and SARS-CoV-2 were published in 2020. Furthermore, there was also an increase in 2020 of publications in other major infectious diseases, such as AIDS, tuberculosis, or malaria. This success is likely the result from the vigorous, international, collaborative, and multidisciplinary response by the research community. During 2020 it was demonstrated, that with adequate support, it is possible to boost the rate of scientific progress in infectious diseases. Sustained investment in science will be key to address existing and future pandemics as the human population increases.
\end{abstract}

Keywords: COVID-19; SARS-CoV-2; Infectious disease; Pandemics; Epidemics; Biomedical Research

\section{Introduction}

Although COVID-19 has often been reported as an "unpredictable catastrophe" it is important to point out that SARS-CoV-2 followed a natural pattern of evolution leading to an epidemic that was predictable in the light of the previous SARS and MERS outbreaks. Indeed, research produced more than a decade ago demonstrated the existence of a vast diversity of coronaviruses in animal reservoirs, some of which having a strong potential to cause human epidemics [1,2]. Had our society's priorities and funding policies for science been different and the scientific progress could had been more, perhaps enabling us to master the development of vaccines and antivirals against Coronoviridae before the year of 2020. The consequence of this lack of vision may have led to the unnecessary loss of millions of human lives and be at the heart of a global economic crisis that could exacerbate inequalities and call into question fundamental human rights. Much of the research that has been carried under the enormous pressure of the COVID-19 pandemic response could arguably been initiated earlier. In this review we explore this topic and the potential impact the biomedical research response to COVID-19 pandemic had on the scientific productivity related to other major infectious human disease, such as AIDS, tuberculosis and malaria. 


\section{The epidemics of SARS-CoV and MERS-CoV}

The family Coronoviridae includes a panoply of envelope-composed viruses and simple-chain RNA that infect birds and mammals [3]. There are at least seven human coronaviruses (HCoV), namely HCoV-229E, HCoV-OC43, HCoV-NL63, HCoV-HKU1, severe acute respiratory syndrome coronavirus (SARS-CoV), Middle East respiratory syndrome coronavirus (MERS-CoV) and the most recent severe acute respiratory syndrome coronavirus (SARS-CoV-2). Unlike SARS-CoV, MERS-CoV and SARS-CoV-2, "common" $\mathrm{HCoV}$ usually cause mild upper respiratory tract disease and contribute seasonally to $15 \%$ to $30 \%$ of cases of "common flu" in adults $[4,5]$.

SARS-CoV and MERS-CoV are zoonotic pathogens that transposed the barrier between species evolving to infect humans. Although the mechanism of zoonotic transfer of viruses are not known in depth, coronaviruses have a protein called "Spike" (S), considered to play a central role in defining the specificity of the virus for a given host. The $S$ protein mediates receptor recognition in host cells and also depends on host factors such as proteases with different specificities to be cleaved and become functional on a given host [6].

The first severe epidemic caused by coronavirus dates to November 2002, with the transmission among people of the SARS-CoV virus. Symptoms of SARS include fever, malaise, headache, diarrhea, among others, and there is no specific symptom scan that allows for diagnosis of the disease. The origin of the SARS outbreak was presumably the infection of people with virus originating from bats in a market with live animals in Guangdong, China [7]. This highly contagious coronavirus, with high mortality rate (9.6\%), infected between 2002 and 2003, more than 8,000 people, killed more than 700, and reached at least 26 countries [8]. It consigned periods of quarantine and travel restrictions that led to estimated economic losses totaling US $\$ 40$ billion, corresponding to losses of around $2.6 \%$ of GDP in China, 1.05\% in Hong Kong and 0.15\% in Canada [9]. The period of greatest likelihood of an infected person transmitting SARS-CoV was described in the second week of disease, at the peak of viral loads in the host, time at which symptoms were regularly evident [10]. This feature of the disease may have helped in the implementation of appropriate protection practices. Indeed, in light of the remarkable effort made, it was possible to fully control the SARS-CoV epidemic at the end of May 2003. Since then, the transmission between people of the SARS-CoV seems to have stopped, with the exception of sporadic cases resulting from laboratory accidents [11]. The propensity of coronaviruses to overcome barriers between species and advance to the human host was confirmed again 10 years after the outbreak of SARS by the emergence of the MERS-CoV virus. Health authorities first reported MERS in Saudi Arabia in September 2012. However, a retrospective study suggests that the first cases of MERS may date from April 2012 in Jordan [12]. By November 2019, all cases of MERS were epidemiologically linked to the Arabian Peninsula, and this disease spread across 27 countries. The largest known outbreak of MERS outside this region occurred in the Republic of Korea in 2015 and was related to a traveler returning from the Arabian Peninsula. At the end of November 2019, a total of 2,494 confirmed cases of MERS were counted by the WHO, resulting in 858 deaths [13].

\section{The emergence and global spread of SARS-CoV-2}

The most likely and highly consensual hypothesis among the scientific community is that in the origin of SARS-CoV-2 was a process of natural selection and zoonotic transfer similar to that which led, in the past, to the emergence of SARS-CoV or MERS-CoV. The order of occurrence of the stages and the animal reservoirs involved in this process are not fully known. It is possible that the virus has undergone natural selection still in the animal host, becoming more adapted to humans, and then transmitted to man. Alternatively, there may have been one or more contact events between infected people and animals in which the virus was transferred to the human host and the process of natural 
selection of the virus occurred already in man [14]. An animal imminently implicated in the ancestry of the virus, despite the likely involvement of other intermediates, is the bat of the species Rhinolophus affinis. This deduction stems from the fact that a coronavirus, called RATG13, whose genome is $96 \%$ identical to the Genome of SARS-CoV-2 was isolated from this bat species in 2013 in China [15]. Phylogeographic analysis of thousands of SARS-CoV-2 genomes isolated worldwide point to the virus emerging in China in November 2019 [16]. These estimates coincide with the first public reports of the disease in Wuhan, a city of 11 million people in Hubei Province, China. The first infections with SARS-CoV-2 in Europe were in January 2020 [17]. The COVID-19 surveillance promoted by WHO was implemented in Europe on 27 January. On February 21, nine European countries recorded 47 cases [18]. At the beginning of July 2020, mortality caused by the COVID-19 pandemic was already the second highest among infectious diseases globally, being only subaltern to tuberculosis mortality [13]. In following months COVID-19 become the deadliest infectious disease in 2020.

The participation of presymptomatic or asymptomatic people in the transmission of SARS-CoV-2 may have been a decisive factor in promoting the rapid geographic expansion of the virus. Individuals infected with SARS-CoV-2 may experience no symptoms when testing positive for symptoms later (presymptomatic) or may not show any symptoms throughout the SARS-CoV-2 infection cycle (asymptomatic). These people do not suspect that they are infected and are a challenge to transmission control measures. Studies reported percentages of individuals infected with SARS-CoV-2 who do not present symptoms at the time of the test between 20 and $80 \%$ [19-21]. These percentages place SARS-CoV-2 close to the estimated values for influenza, where the estimated proportion of asymptomatic infections is from 50 to $75 \%[22,23]$. The existence of these reservoirs of asymptomatic people contributes to the success and seasonal reappearance of the influenza virus. However, it is important to point out that the influenza virus is very different from SARS-CoV-2. For example, the mutation rate of influenza is higher allowing it to evade the immune system in a process known as antigenic drift [24]. This mechanism is considered central to the seasonal manifestation of new effective strains of influenza virus from pre-existing reservoirs [24]. Regarding SARS-CoV-2, the delay in recognizing the high numbers of infections in people without symptoms and the likelihood of them transmitting the virus had probable implications in the initial failure of isolation policies and strategies for testing. There is a heterogeneity of factors that relate to the transmission of respiratory viruses, namely the different patterns of contact between individuals, levels of immunity, environmental variables, among others. A study characterizing 318 transmission chains of SARS-CoV-2 showed that most transmission cases occurred in indoor spaces [25]. Thus, the sharing of interior spaces associated with a higher risk of Infection by SARS-CoV-2 when compared with concomitance in outdoor spaces. The factors at the basis of this difference remain to be clearly circumscribed, but it is possible that the shorter contact time and less proximity between people, temperature, wind, or sunlight play an influential role in reducing the likelihood of transmission of the virus outside [26]. In an open letter published on 6 July 2020, 239 scientists from 32 countries warn about the potential for aerial transmission of SARS-CoV-2 [27]. The authors write that a growing set of scientific evidence showed "beyond any reasonable doubt" that the virus is transmitted through aerosols, small particles capable of circulating in the air for long periods and that this finding should be reflected in the recommendations of WHO.

Another aspect possibly relevant in the continued vigorous expansion of SARS-CoV2 in the end of 2020 was the appearance of genetic lineages of the virus that accumulated several mutations when compared with the initial viral isolate from Wuhan. A notable example was the so-called SARS-CoV-2 "UK variant" or B.1.1.7 lineage that was detected in December 2020 in the UK and rapidly increased in frequency in the country and abroad. A possible explanation for the success of this SARS-CoV-2 lineage was the accumulation of non-synonymous mutations and deletions in the $S$ protein that could influence the interaction with human receptors and factors facilitating viral entry in the host cell [28]. The 
relevance of the mutations widely described in the SARS-CoV-2 genome during the pandemic and the possible evolution of the virus during the person-to-person transmission is a topic under in-depth scientific study. In addition to a potential impact in viral transmissibility or virulence another relevant consequence of some of the SARS-CoV-2 mutations possibly related to evolutionary processes is the interference with the sensitivity of molecular diagnostic methods for virus detection [29] that could also add to the difficulties in controlling the pandemics.

\section{Biomedical research during the COVID-19 pandemic}

When the COVID-19 pandemic was installed, a "revolution" in research began, leading scientists, physicians, and other related professionals to work at large speeds to find ways to better understand and combat the SARS-CoV-2 virus. This movement was truly multidisciplinary and in no way restricted to specialists in virology. Several researchers quickly reoriented research efforts and made available all scientific knowledge that could meet, in the short and medium term, the needs imposed by the new pandemic. This movement encompassed the exploration and understanding of fundamental biological processes associated with SARS-CoV2, namely its spread, invasion, replication and evolution and its application in the fight against this pandemic. Several projects were rapidly initiated for the development of vaccines, effective therapies, and specific, sensitive and rapid diagnostic tests. The multidisciplinary efforts produced included not only the most scientifically related areas such as medicine, microbiology, virology, immunology, or epidemiology, but also several areas that would be theoretically less related such as engineering, technology, economics, social sciences or psychiatry. The reorientation of the scientific community towards the response to COVID-19 was also fostered by the rapid commitment and provision of funding from various government and private entities at national and international level. This "revolution" in scientific activity had an almost immediate impact on scientific work produced worldwide. The response has been immediate and intense, at a speed that goes beyond what was thought possible. In just six months into the COVID-19 pandemic the published volume of scientific work generated was already much higher than historically had been produced for other human infectious diseases. As of July 2020, more than 87267 publications (including "pre-publications", scientific articles, book chapters, monographs and procedures) were published on SARS-CoV2/COVID-19, and 4621 clinical trials initiated [30]. Considering this remarkable success, one could question if it had been done at the cost of a loss of productivity in the biomedical research focused on other major human health diseases. Using the PubMed services portal and comparing the volume of scientific articles published from 2015-2020 suggests otherwise. The total number of PubMed-indexed publications in 2020 increased in more than $8 \%$ when compared with the number of publications reported in 2019 or comparing with the yearly average of publications in the last five previous years (Figure 1A). This increase was not related with changes in the article type since the publication of reviews and books indexed in this database remained stable across the years (Figure 1A). To this boost in productivity contributed a remarkable number of publications related with COVID-19 and SARS-CoV-2 in 2020 (86,638 publications, Figure 1B). Interestingly, an increase in productivity was also observed in the research related to other major infectious diseases, such as AIDS, tuberculosis or malaria (Figure 1B). 


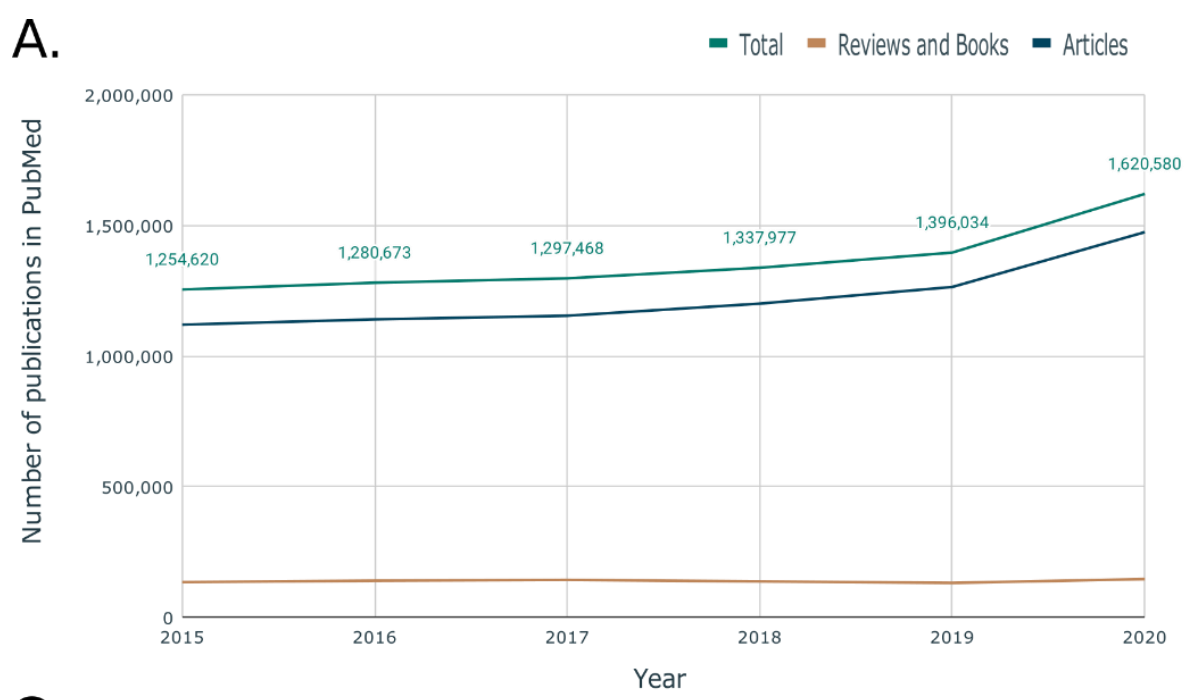

B.

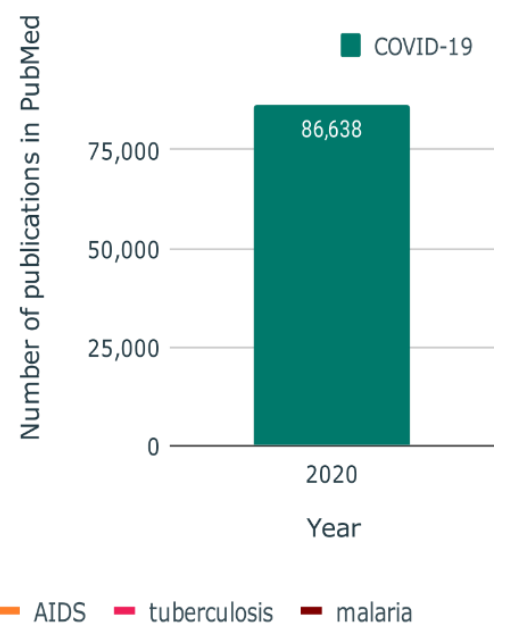

C.

- AIDS - tuberculosis - malaria

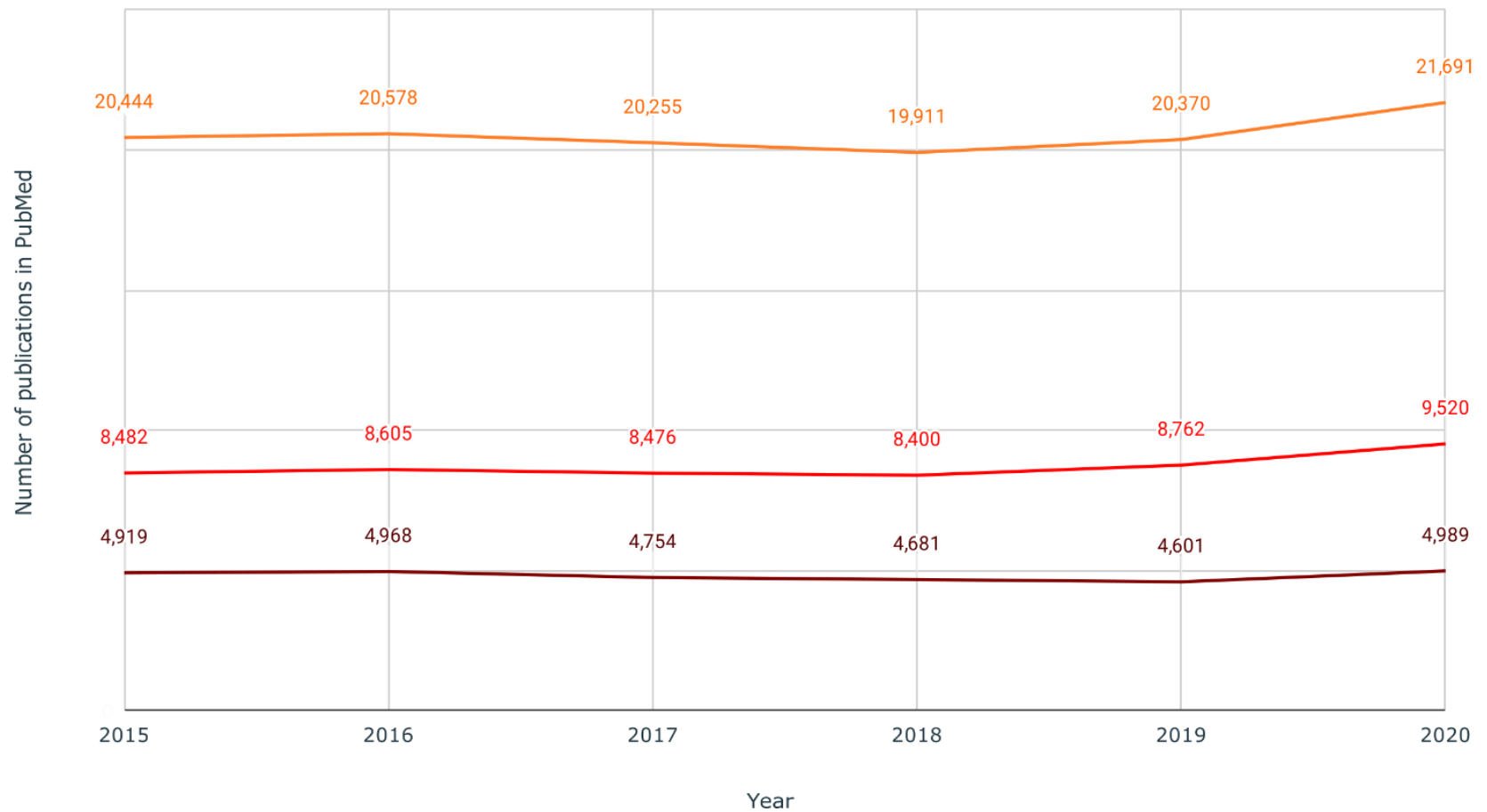

Figure 1. Number of publications in the PubMed database in the years 2015-2020. A. total number of publications and data segmented by article type. B. Scientific articles published in the PubMed database since in 2020 on COVID-19. C. Articles published from 2015-2020 in the infectious diseases that globally caused the most deaths in the last decade (Malaria, Tuberculosis and AIDS). The data were collected by querying the PudMed database with the keywords "COVID-19", "SARS-CoV-2", "Malaria", "Tuberculosis", "AIDS" and "HIV" on 16 February 2021.

\section{Conclusion}

During the year of 2020, in response to the COVID-19 pandemic, there was a vigorous, international, collaborative, and multidisciplinary response by the research community that, supported by adequate funding and policies, boosted the productivity in biomedical research. Importantly, this was observed not only in the topic of COVID-19 and SARS-CoV-2 but also in other major infectious diseases, such as AIDS, tuberculosis and malaria. Despite the frantic pace, only sporadically, the abusive interpretation of studies without scientific review (preprints) or even the hasty publication of lower quality studies led to the dissemination of erroneous conceptions. A widely publicized example, rapidly and distinctly refuted [14], were the theories that SARS-CoV-2 virus had been genetically engineered. Although, the society still runs against time in the incessant search for an- 
swers on COVID-19 and how to fight the SARS-CoV-2, the response and impact from biomedical research was deeply beneficial. The development and approval of COVID-19 vaccines in record time was only one and the most visible of several remarkable scientific achievements of the year. What happen in 2020 in the field of biomedical research, and its comparison with the previous years, was a vibrant demonstration that it is possible to do more and advance science at a faster pace. It is hard not to regret that, had our society's priorities and funding policies for science been different, and scientific progress could have enabled us to avoid, or at least minimize, the harmful impacts of the COVID-19 pandemic. This was not the case and millions of lives were and continue to be lost to COVID19 that also imposed a profound global economic crisis of unknown contour. For one year, a path of knowledge was followed from the identification of the etiological agent of COVID-19, to a better understanding of its origin, evolution, transmission, immune response, treatment, susceptibility factors to severe disease, among other. The beneficial impact of this scientific productivity boost in biomedicine is only now starting to become visible and is likely to lead to a better control of the COVID-19 pandemic in the near future. The impact on the other major infectious diseases, that are responsible for massive morbidity and millions of lives lost every year in the last decades, mainly in developing countries, is harder to predict. Unfortunately, the boost in productivity in biomedical research during the COVID-19 may not be sustained if the policy makers and ultimately, the society as whole, regress to old priorities. This will likely undermine the pace of progress in the combat of the "big three" (HIV/ADIS, tuberculosis, malaria) and other relevant infectious diseases. We should raise awareness that, due to the increase in human population and globalization, pandemics are likely an emerging and recurrent problem of modern society. Thus, the SARS-CoV-2 pandemic should lead us to reflect on the priorities of our society and the importance of a bigger and more sustained investment in science.

Funding: This work has been funded by Portuguese National funds, through the Foundation for Science and Technology (FCT) (project UIDB/50026/2020 and UIDP/50026/2020; and contract funding to M.I.V. provided through DL 57/2016 (CRP)); by the projects NORTE-01-0145-FEDER-000013 and NORTE-01-0145-FEDER-000023, supported by Norte Portugal Regional Operational Programme (NORTE 2020), under the PORTUGAL 2020 Partnership Agreement, through the European Regional Development Fund (ERDF)

Conflicts of Interest: The authors declare no conflict of interest.

\section{References}

1. Li, W.; Shi, Z.; Yu, M.; Ren, W.; Smith, C.; Epstein, J. H.; Wang, H.; Crameri, G.; Hu, Z.; Zhang, H.; Zhang, J.; McEachern, J.; Field, H.; Daszak, P.; Eaton, B. T.; Zhang, S.; Wang, L.-F., Bats Are Natural Reservoirs of SARS-Like Coronaviruses. Science 2005, 310, (5748), 676-679.

2. Ge, X.-Y.; Li, J.-L.; Yang, X.-L.; Chmura, A. A.; Zhu, G.; Epstein, J. H.; Mazet, J. K.; Hu, B.; Zhang, W.; Peng, C.; Zhang, Y.-J.; Luo, C.-M.; Tan, B.; Wang, N.; Zhu, Y.; Crameri, G.; Zhang, S.-Y.; Wang, L.-F.; Daszak, P.; Shi, Z.-L., Isolation and characterization of a bat SARS-like coronavirus that uses the ACE2 receptor. Nature 2013, 503, (7477), 535-538.

3. $\quad$ Payne, S., Chapter 17 - Family Coronaviridae. In Viruses, Payne, S., Ed. Academic Press: 2017; pp 149-158.

4. Liu, D. X.; Liang, J. Q.; Fung, T. S., Human Coronavirus-229E, -OC43, -NL63, and -HKU1. In Reference Module in Life Sciences, Elsevier: 2020.

5. Woo, P. C.; Lau, S. K.; Yip, C. C.; Huang, Y.; Yuen, K. Y., More and More Coronaviruses: Human Coronavirus HKU1. Viruses 2009, 1, (1), 57-71.

6. Hulswit, R. J.; de Haan, C. A.; Bosch, B. J., Coronavirus Spike Protein and Tropism Changes. Adv Virus Res 2016, 96, $29-57$. 
7. Zhong, N. S.; Zheng, B. J.; Li, Y. M.; Poon; Xie, Z. H.; Chan, K. H.; Li, P. H.; Tan, S. Y.; Chang, Q.; Xie, J. P.; Liu, X. Q.; Xu, J.; Li, D. X.; Yuen, K. Y.; Peiris; Guan, Y., Epidemiology and cause of severe acute respiratory syndrome (SARS) in Guangdong, People's Republic of China, in February, 2003. Lancet 2003, 362, (9393), 1353-8.

8. Wang, J. T.; Chang, S. C., Severe acute respiratory syndrome. Curr Opin Infect Dis 2004, 17, (2), 143-8.

9. Website International Dimensions of Ethics Education. . https://www.umass.edu/sts/ethics/sars.html (accessed on 16 Feb 2021),

10. Petersen, E.; Koopmans, M.; Go, U.; Hamer, D. H.; Petrosillo, N.; Castelli, F.; Storgaard, M.; Al Khalili, S.; Simonsen, L., Comparing SARS-CoV-2 with SARS-CoV and influenza pandemics. Lancet Infect Dis 2020.

11. Lim, P. L.; Kurup, A.; Gopalakrishna, G.; Chan, K. P.; Wong, C. W.; Ng, L. C.; Se-Thoe, S. Y.; Oon, L.; Bai, X.; Stanton, L. W.; Ruan, Y.; Miller, L. D.; Vega, V. B.; James, L.; Ooi, P. L.; Kai, C. S.; Olsen, S. J.; Ang, B.; Leo, Y. S., Laboratory-acquired severe acute respiratory syndrome. N Engl J Med 2004, 350, (17), 1740-5.

12. Hijawi, B.; Abdallat, M.; Sayaydeh, A.; Alqasrawi, S.; Haddadin, A.; Jaarour, N.; Alsheikh, S.; Alsanouri, T., Novel coronavirus infections in Jordan, April 2012: epidemiological findings from a retrospective investigation. East Mediterr Health J 2013, 19 Suppl 1, S12-8.

13. WHO Middle East respiratory syndrome coronavirus (MERS-CoV). https://www.who.int/emergencies/mers-cov/en/ (accessed on 16 Feb 2021),

14. Andersen, K. G.; Rambaut, A.; Lipkin, W. I.; Holmes, E. C.; Garry, R. F., The proximal origin of SARS-CoV-2. Nat Med 2020, 26, (4), 450-452.

15. Zhou, P.; Yang, X. L.; Wang, X. G.; Hu, B.; Zhang, L.; Zhang, W.; Si, H. R.; Zhu, Y.; Li, B.; Huang, C. L.; Chen, H. D.; Chen, J.; Luo, Y.; Guo, H.; Jiang, R. D.; Liu, M. Q.; Chen, Y.; Shen, X. R.; Wang, X.; Zheng, X. S.; Zhao, K.; Chen, Q. J.; Deng, F.; Liu, L. L.; Yan, B.; Zhan, F. X.; Wang, Y. Y.; Xiao, G. F.; Shi, Z. L., A pneumonia outbreak associated with a new coronavirus of probable bat origin. Nature 2020, 579, (7798), 270-273.

16. van Dorp, L.; Acman, M.; Richard, D.; Shaw, L. P.; Ford, C. E.; Ormond, L.; Owen, C. J.; Pang, J.; Tan, C. C. S.; Boshier, F. A. T.; Ortiz, A. T.; Balloux, F., Emergence of genomic diversity and recurrent mutations in SARS-CoV-2. Infect Genet Evol 2020, $83,104351$.

17. Olsen, S.; Chen, M.-Y.; Liu, Y.-L.; Witschi, M.; Ardoin, A.; Calba, C.; Mathieu, P.; Masserey, V.; Maraglino, F.; Marro, S.; Penttinen, P.; Robesyn, E.; Pukkila, J., Early Introduction of Severe Acute Respiratory Syndrome Coronavirus 2 into Europe. Emerging Infectious Disease journal 2020, 26, (7), 1567.

18. Spiteri, G.; Fielding, J.; Diercke, M.; Campese, C.; Enouf, V.; Gaymard, A.; Bella, A.; Sognamiglio, P.; Sierra Moros, M. J.; Riutort, A. N.; Demina, Y. V.; Mahieu, R.; Broas, M.; Bengnér, M.; Buda, S.; Schilling, J.; Filleul, L.; Lepoutre, A.; Saura, C.; Mailles, A.; Levy-Bruhl, D.; Coignard, B.; Bernard-Stoecklin, S.; Behillil, S.; van der Werf, S.; Valette, M.; Lina, B.; Riccardo, F.; Nicastri, E.; Casas, I.; Larrauri, A.; Salom Castell, M.; Pozo, F.; Maksyutov, R. A.; Martin, C.; Van Ranst, M.; Bossuyt, N.; Siira, L.; Sane, J.; Tegmark-Wisell, K.; Palmérus, M.; Broberg, E. K.; Beauté, J.; Jorgensen, P.; Bundle, N.; Pereyaslov, D.; Adlhoch, C.; Pukkila, J.; Pebody, R.; Olsen, S.; Ciancio, B. C., First cases of coronavirus disease 2019 (COVID-19) in the WHO European Region, 24 January to 21 February 2020. Eurosurveillance 2020, 25, (9), 2000178.

19. Bi, Q.; Wu, Y.; Mei, S.; Ye, C.; Zou, X.; Zhang, Z.; Liu, X.; Wei, L.; Truelove, S. A.; Zhang, T.; Gao, W.; Cheng, C.; Tang, X.; Wu, X.; Wu, Y.; Sun, B.; Huang, S.; Sun, Y.; Zhang, J.; Ma, T.; Lessler, J.; Feng, T., Epidemiology and transmission of COVID19 in 391 cases and 1286 of their close contacts in Shenzhen, China: a retrospective cohort study. Lancet Infect Dis 2020.

20. Hoxha, A.; Wyndham-Thomas, C.; Klamer, S.; Dubourg, D.; Vermeulen, M.; Hammami, N.; Cornelissen, L., Asymptomatic SARS-CoV-2 infection in Belgian long-term care facilities. Lancet Infect Dis 2020.

21. Sutton, D.; Fuchs, K.; D'Alton, M.; Goffman, D., Universal Screening for SARS-CoV-2 in Women Admitted for Delivery. N Engl J Med 2020, 382, (22), 2163-2164.

Hayward, A. C.; Fragaszy, E. B.; Bermingham, A.; Wang, L.; Copas, A.; Edmunds, W. J.; Ferguson, N.; Goonetilleke, N.; Harvey, G.; Kovar, J.; Lim, M. S.; McMichael, A.; Millett, E. R.; Nguyen-Van-Tam, J. S.; Nazareth, I.; Pebody, R.; Tabassum, 
F.; Watson, J. M.; Wurie, F. B.; Johnson, A. M.; Zambon, M.; Flu Watch, G., Comparative community burden and severity of seasonal and pandemic influenza: results of the Flu Watch cohort study. Lancet Respir Med 2014, 2, (6), 445-54.

23. Horby, P. W., Community studies of influenza: new knowledge, new questions. Lancet Respir Med 2014, 2, (6), 430-1.

24. Rambaut, A.; Pybus, O. G.; Nelson, M. I.; Viboud, C.; Taubenberger, J. K.; Holmes, E. C., The genomic and epidemiological dynamics of human influenza A virus. Nature 2008, 453, (7195), 615-9.

25. Qian, H.; Miao, T.; LIU, L.; Zheng, X.; Luo, D.; Li, Y., Indoor transmission of SARS-CoV-2. medRxiv 2020, 2020.04.04.20053058.

26. Takagi, H.; Kuno, T.; Yokoyama, Y.; Ueyama, H.; Matsushiro, T.; Hari, Y.; Ando, T., Higher Temperature, Pressure, and Ultraviolet Are Associated with Less COVID-19 Prevalence: Meta-Regression of Japanese Prefectural Data. medRxiv 2020, 2020.05.09.20096321.

27. Morawska, L.; Milton, D. K., It is Time to Address Airborne Transmission of COVID-19. Clinical Infectious Diseases 2020.

28. GOV.UK Investigation of novel SARS-CoV-2 variant: Variant of Concern $202012 / 01$. https://assets.publishing.service.gov.uk/government/uploads/system/uploads/attachment_data/file/959438/Technical_Brie fing_VOC SH_NIL2_SH2.pdf (accessed on 16 Feb 2021),

29. Osorio, N. S.; Correia-Neves, M., Implication of SARS-CoV-2 evolution in the sensitivity of RT-qPCR diagnostic assays. Lancet Infect Dis 2020.

30. App.Dimensions Dimensions is facilitating access to COVID-19 research. https://covid-19.dimensions.ai (accessed on 20 Jul 2020), 